OPEN ACCESS

Edited by:

Rengaraj Selvaraj,

Sultan Qaboos University, Oman

Reviewed by: Sanjay S. Kolekar,

Shivaji University, India

Zinetula Z. Insepov,

Purdue University, United States

${ }^{*}$ Correspondence:

Abdullah Aljaafari

aaljaafari@kfu.edu.sa

Speciality section:

This article was submitted to

Thin Solid Films,

a section of the journal

Frontiers in Materials

Received: 03 June 2020 Accepted: 29 September 2020

Published: 18 November 2020

Citation:

Aljaafari A (2020) Size Dependent Photocatalytic Activity of $\mathrm{ZnO}$

Nanosheets for Degradation of

Methyl Red.

Front. Mater. 7:562693.

doi: $10.3389 /$ fmats.2020.562693

\section{Size Dependent Photocatalytic Activity of ZnO Nanosheets for Degradation of Methyl Red}

\author{
Abdullah Aljaafari * \\ Department of Physics, College of Science, King Faisal University, Al-Ahsa, Saudi Arabia
}

In this work, ZnO nanosheets with a tunable thickness were produced by a microwaveassisted hydrothermal-based method. The product was well characterized by various tools such as XRD, SEM, EDX spectroscopy, TEM, and Raman spectroscopy. ZnO nanosheets were highly crystalline and possessed a single phase with the wurtzite structure. The $\mathrm{ZnO}$ nanosheets have a thickness ranging from 20 to $50 \mathrm{~nm}$, as shown by the micrographs of SEM. The SAED pattern infered that the ZnO nanosheets have a single crystal nature with preferential growth direction along [0001]. ZnO nanosheets with $\mathrm{E}_{2}{ }^{\text {high }}$ mode of wurtzite structure were observed by Raman scattering spectra. The photodegradation of methyl red using $\mathrm{ZnO}$ nanosheets was measured under UV light irradiation. In comparison with the commercial $\mathrm{ZnO}, \mathrm{ZnO}$ nanosheets showed higher efficiency in photodegradation of organic dyes. The thinner the nanosheets, the higher their performance, which can be explained based on surface area. The excellent performance of $\mathrm{ZnO}$ nanosheets in photodegradable organic dyes might be important in environmental treatment and photocatalysis applications.

Keywords: ZnO, nanosheets (NSs), photocatalyts, XRD, TEM

\section{INTRODUCTION}

Recently, environmental pollution of organic pollutants by photolysis of wide-gapped semiconductors, have attracted great attention (Linsebigler et al., 1995; Chatterjee and Dasgupta, 2005; Comparelli et al., 2005; Thompson and Yates, 2006). Moreover, these nanostructures provide enhancement in the functional properties for potential applications in the fabrication of nanodevices. In photocatalytic applications, numerous semiconducting nanostructurtes, including $\mathrm{ZnO}$ and $\mathrm{TiO}_{2}$, are being used due to their unique properties of low cost, high photosensitivity, non-toxicity and environmentally friendly behavior ( $\mathrm{Wu}$ and Tseng, 2006; Wang et al., 2007). $\mathrm{ZnO}$ has been considered to be a more capable photocatalyst than $\mathrm{TiO}_{2}$ due to its high surface reactivity resulting from a large number of active surface defect states (Kumar and Rao, 2015). Additionally, the more efficient hydroxyl ion production capability (Carraway et al., 1994) of $\mathrm{ZnO}$ provides high reaction and mineralization rates (Poulios et al., 1999; Bohle and Spina, 2009; Wang et al., 2009). The catalytic activity of metal oxide nanostructures is known to depend on surface area and surface defects (Baruah et al., 2008). Among the different dimensions, two-dimensional nanostructures including nanosheets or nanotubes can be considered a new class of nanostructure material due to their high anisotropy, large surface area and nanometer scale thickness, and they have interesting properties (Jang et al., 2006).

The unique structural features of two-dimensional nanomaterials, such as ultrathin thickness and possibly specific open crystal planes, may be useful for a wide range of surface interactions/ 
interactivity-oriented applications, such as electrodes of dyesensitive solar cells, gas sensors, supercapacitors, lithium ion batteries, photocatalytic water splitting, photocatalysis, etc. (Hosono et al., 2005; Jing and Zhan, 2008; Liu et al., 2009; Qiu et al., 2010; Zhang et al., 2009a). ZnO crystals are composed of closely packed $\mathrm{O}^{2-}$ layers piled alternatively along the c-axis, producing positively charged $\mathrm{Zn}$-terminated (0001) polar surfaces and negatively charged O-terminated (000) polar surfaces (Kong and Wang, 2004). ZnO crystals have a non-central symmetric wurtzite structure. The average surface energy of $\mathrm{ZnO}$ for the polar $\pm\{0001\}$ plane is higher than non-polar $\{01 \overline{\mathrm{i}} 0\}$, and $\{2 \overline{\mathrm{i}} \overline{\mathrm{i}} 0\}$ planes. It can be expected that the higher-surface-energy $\pm(0001)$ surface has much higher amounts of chemical activity (Kong and Wang, 2004).

Therefore, the development of a synthesis technique for the shape and size of tunable $\mathrm{ZnO}$ nanostructures is needed. Numerous reports have shown the growth of $\mathrm{ZnO}$ nanostructures in various dimensions inclduing nanowires, nanobelts, nanorods, nanosheets, and nanotubes (Huang et al., 2001; Pan et al., 2001; Wu et al., 2002; Tien et al., 2007; Baruah and Dutta, 2009; Becker et al., 2011). Also, ZnO nanosheets have been synthesized by using different chemical and physical methods such as thermal evaporation, chemical vapor deposition (CVD), physical vapor deposition (PVD), electrochemical processes, hydrothermal or solvothermal methods (Zhang et al., 2003; Zeng et al., 2005; Hu et al., 2008; Li et al., 2008; Qiu et al., 2009). However, these methods have disadvantages due to their high-temperatures, vacuum conditions, or longer reaction times, which make these techniques expensive. Thus, to fulfill economic and industrial necessities, a quick and easy process for the synthesis of $\mathrm{ZnO}$ nanostructures under ambient conditions is required. Nevertheless, the controlled growths of $\mathrm{ZnO}$ nanosheets with the thickness in quantum confinement range and their thickness dependent photocatalytic properties have not been reported. More recently, microwave radiation has introduced the synthesis of nanomaterials. Compared with conventional heating, microwave heating has unique effects such as fast and homogeneous volumetric heating, high reaction rate, short reaction time, improved reaction selectivity, energy saving and low cost (Ahmed et al., 2011).

In this work, a simple microwave-assisted hydrothermal assisted solution method was used to prepare $\mathrm{ZnO}$ nanosheets containing highly reactive (0001) facets and tunable thickness. The dependence of photocatalytic degradation of methyl red dye on the thickness of $\mathrm{ZnO}$ nanosheets was investigated. It is worth mentioning that the present products possessed higher specific surface areas and smaller nanosheet thicknesses in quantum confinement range than products from both microwave-assisted processes, and hydrothermal (Zhou et al., 2008; Qiu et al., 2010). Most importantly, there is no requirement of further calcination steps to obtain the final product as is required in earlier reports (Dong et al., 2012). The $\mathrm{ZnO}$ nanosheets prepared by the present process possessed single-crystallinity, high surface areas, and ultrathin thicknesses, characteristics which are beneficial for photocatalytic applications.

\section{EXPERIMENTAL DETAILS}

The product was synthesed using the microwave hydrothermal method (CEM; MARS 5). Potassium hydroxide (KOH; 99.99\%) and Zinc acetate dihydrate $\left(\mathrm{Zn}\left(\mathrm{CH}_{3} \mathrm{COO}\right)_{2} .2 \mathrm{H}_{2} \mathrm{O}\right.$; 99.999) were mainly used in experiments. Different molar ratios of 1:2.5 (sample 1), 1:2.75 (sample 2), 1:5 (sample 3) of $\mathrm{Zn}\left(\mathrm{CH}_{3} \mathrm{COO}\right)_{2} .2 \mathrm{H}_{2} \mathrm{O}$ and $\mathrm{KOH}$ were dissolved in a roundbottom flask which included $100^{\circ} \mathrm{ml}$ water. The mixture was then transferred to a Teflon-lined digestion vessel of $100^{\circ} \mathrm{ml}$ and operated at $160^{\circ} \mathrm{C}$ and 100 psi for $20 \mathrm{~min}$ in a microwave system. The operating power used was $1200 \mathrm{~W}$. The temperature was observed during irradiation by a thermocouple fixed into the reference vessel. After the process, the product was allowed to cool down to room temperatue. Centrifuge was used to separate the precipitate which was washed with deionized water and absolute ethanol several times. The product was then dried in an oven at $80^{\circ} \mathrm{C}$ for $24 \mathrm{~h}$.

For photocatalysis experiments, methyl red (MR) was used as a test pollutant. An aqueous solution of $\mathrm{MR}(10 \mu \mathrm{M})$ was used corresponding to $\mathrm{ZnO} \quad(10 \mathrm{mg})$. To attain an adsorption-desorption equilibrium, the suspension was then stirred in the dark for $30 \mathrm{~min}$. A mercury lamp of high pressure was used as a light source radiation. After the time interval, $5 \mathrm{ml}$ was withdrawn and centrifugated immediately to remove the photocatalyst particles. Then it was analyzed by a UVVis spectrophotometer (Agilent 8453) to observe the spectra MR. For the photocatalytic stability of $\mathrm{ZnO}$ nanosheets, a time track of photocatalytic degradation of $\mathrm{MR}$ using photocatalyst was conducted.

X-ray diffraction (Phillips X'pert (MPD-3040)) was used to investigate the phase purity of the product obtained with $\mathrm{Cu} \mathrm{Ka}$ radiations $(\lambda=1.5406 \AA$ ). Field emission electron microscopy (FESEM) images were obtained using a MIRA II LMH microscope and initial synthesis of $\mathrm{ZnO}$ was obtained by energy dispersing X-ray spectroscopy (EDX, Inca Oxford) attached to FESEM.

The electron microscopy (TEM) and electron diffraction pattern for the selected area (SAED) and high-resolution transmission electron microscopy (HRTEM) micrographs were obtained using FE-TEM (JEOL/JEM-2100F version). $\mathrm{ZnO}$ nanosheets were first dispersed in ethanol solution followed by ultrasound treatment for $10 \mathrm{~min}$ for TEM analysis. Furthermore, a fine drop of $\mathrm{ZnO}$ suspension was cast onto a carbon-covered copper mesh and then dried in the air before being transferred to the microscope. The Micro-Raman spectrometer (NRS-3100) was used to obtain a phonon vibrational of $\mathrm{ZnO}$ nanostructures, with a solid $532 \mathrm{~nm}$ primary laser as an excitation source in configuring background dispersion at room temperature. Optical absorption spectra of room temperature were recorded in the range of $200-800 \mathrm{~nm}$ using the UV-vis optical spectrophotometer (Agilent-8453). BrunauerEmmett-Teller (BET) surface area measurements were performed by nitrogen adsorption using Autosorb-1 (Quantachrome Instruments, Boynton Beach, FL, United States). 


\section{RESULTS AND DISCUSSION}

$\mathrm{XRD}$ patterns of $\mathrm{ZnO}$ nanosheets prepared at different $\mathrm{KOH}$ concentrations are shown in Figures 1A. The diffraction peaks were indexed to the hexagonal wurtzite $\mathrm{ZnO}$ phase (JCPDS 891397) with calculated lattice parameters a and $c$ to be 3.249 and $5.207 \AA$, respectively. It can also be seen that all the samples showed a single-phase nature with a wurtzite structure (Marković et al., 2019). As the molar ratio was increased from $1: 2.5$ to $1: 5$, the peak became more intense which signified better crystallinity.

High-resolution transmission electron microscopy (HRTEM) revealed the atomic structures of $\mathrm{ZnO}$ nanosheets. The HRTEM image (Figures 1B) also shows that the $\mathrm{ZnO}$ nanosheets (sample 1) were highly crystalline, having a lattice spacing of about $0.26^{\circ} \mathrm{nm}$, corresponding to the distance between the (002) planes in $\mathrm{ZnO}$ crystal lattice. Also, selected-area electron diffraction (SAED) patterns of the same $\mathrm{ZnO}$ nanosheets (sample 1) were indexed to hexagonal $\mathrm{ZnO}$, which also indicated that the $\mathrm{ZnO}$ nanosheets were single crystalline and had growth along the [001] direction. These results are also in good aggrement with the XRD results.

Energy dispersive X-ray spectroscopy (EDX) was used for elemental composition of the $\mathrm{ZnO}$ nanosheets. The EDX spectrum (Figures. 1C) shows peaks of $\mathrm{Zn}$ and $\mathrm{O}$ for all the $\mathrm{ZnO}$ nanosheets, which signifies that the $\mathrm{ZnO}$ nanosheets were composed of $\mathrm{Zn}$ and $\mathrm{O}$ only and no impurity peaks were found, confirming high purity of $\mathrm{ZnO}$ nanosheets.

Figure 2 shows FESEM images of the $\mathrm{ZnO}$ nanosheets with different thicknesses obtained from the varying concentration of $\mathrm{KOH}$. Figures $2 \mathrm{~A}$ represents the morphology of the $\mathrm{ZnO}$ nanosheets (sample 1) with a lateral dimension of $\sim 500 \mathrm{~nm}$ and thickness of $\sim 24 \mathrm{~nm}$, respectively with a molar ratio of 1 : 2.5. The thickness of the samples was measured by using "Image J" software which is a strong tool for the TEM and SEM analysis. For the measurement, nanosheets in the images were chosen randomly, and the lateral size and thickness were measured accurately. Using ImageJ, one can measure the size in nanorange with more precision, thus the thickness was reported. With the increase of the molar ratio to 1:2.75 (sample 2), the lateral dimension of nanosheets decreased to $\sim 360 \mathrm{~nm}$, with a slight increase in the thickness to $\sim 29 \mathrm{~nm}$ (Figures 2B). On further increasing the molar ratio to 1:5 (sample 3) (Figures 2C), $\mathrm{ZnO}$ nanosheets with lateral dimension $\sim 240 \mathrm{~nm}$, thickness $\sim 50 \mathrm{~nm}$ aspect ratio $\sim 37$ were obtained. Hence, it can be seen that as the lateral dimension of the nanosheets decreases, the thickness increases with the increasing molar ratio, concluding that $\mathrm{ZnO}$ morphology is molar ratio dependent.

Figure 3 depicts the room temperature Raman spectra of $\mathrm{ZnO}$ nanosheets for different molar ratios of zinc acetate and $\mathrm{KOH}$. The Raman spectrum (Figure 3) of $\mathrm{ZnO}$ nanosheets confirms conventional vibration modes (Cusco et al., 2007) of $\mathrm{E}_{2}{ }^{\text {high }}-\mathrm{E}_{2}{ }^{\text {low }}$, $\mathrm{A}_{1}$ (TO), and $\mathrm{E}_{2}^{\text {high }}$, centered at $332 \mathrm{~cm}^{-1}, 381 \mathrm{~cm}^{-1}$, and $439 \mathrm{~cm}^{-1}$, respectively. These results commensurate with the XRD results. Further, with the increase in molar ratio the intensity of $\mathrm{E}_{2}^{\text {high }}$ mode varies, this change in the intensity of Raman modes is due to increase in supersaturation (Nagy and Casey, 1971).

To study the specific surface area of the nanosheets with various thicknesses, BET analysis was carried out. BET analysis of the sample one showed a surface area of $182^{\circ} \mathrm{m}^{2} / \mathrm{g}$,
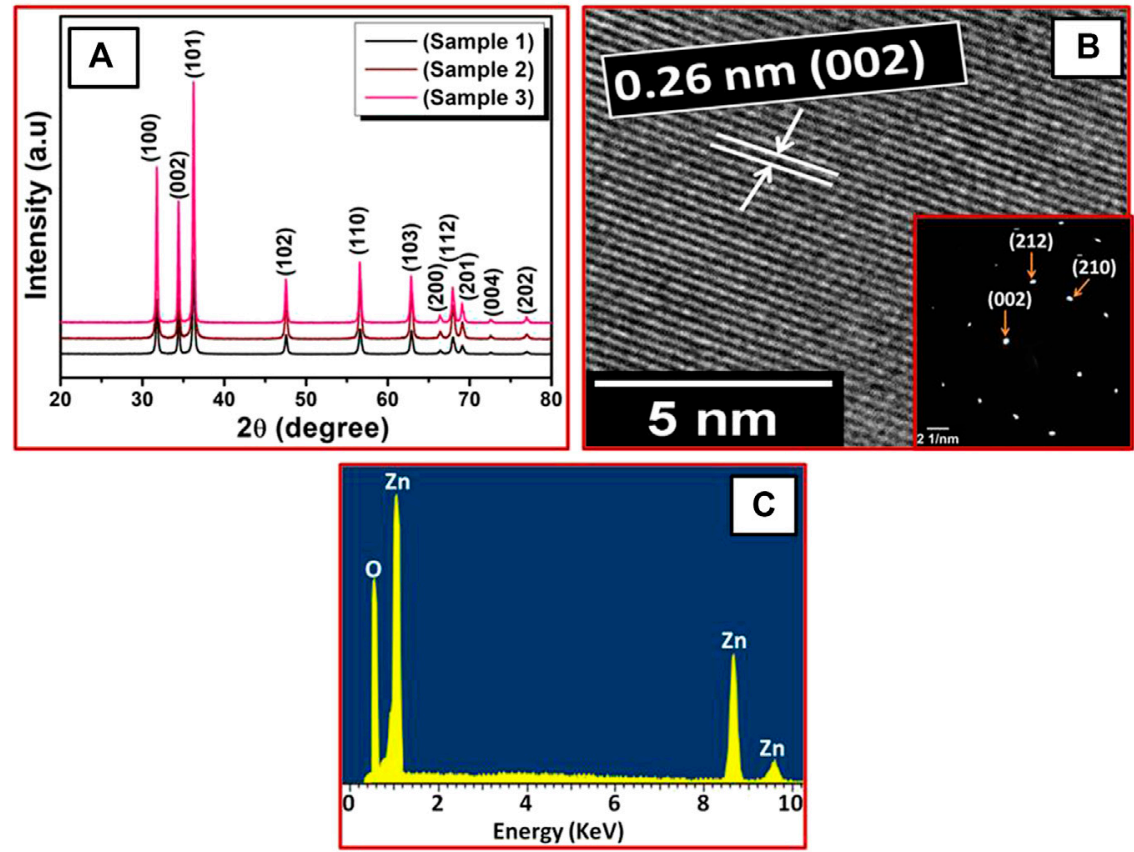

FIGURE 1 | (A) XRD patterns of ZnO nanosheets for different molar ratios of zinc acetate and KOH: sample 1 (1:2.5), sample 2 (1:2.75), sample 3 (1:5). (B) HRTEM and SAED patterns of sample 1, (C) corresponding EDX spectrum. 

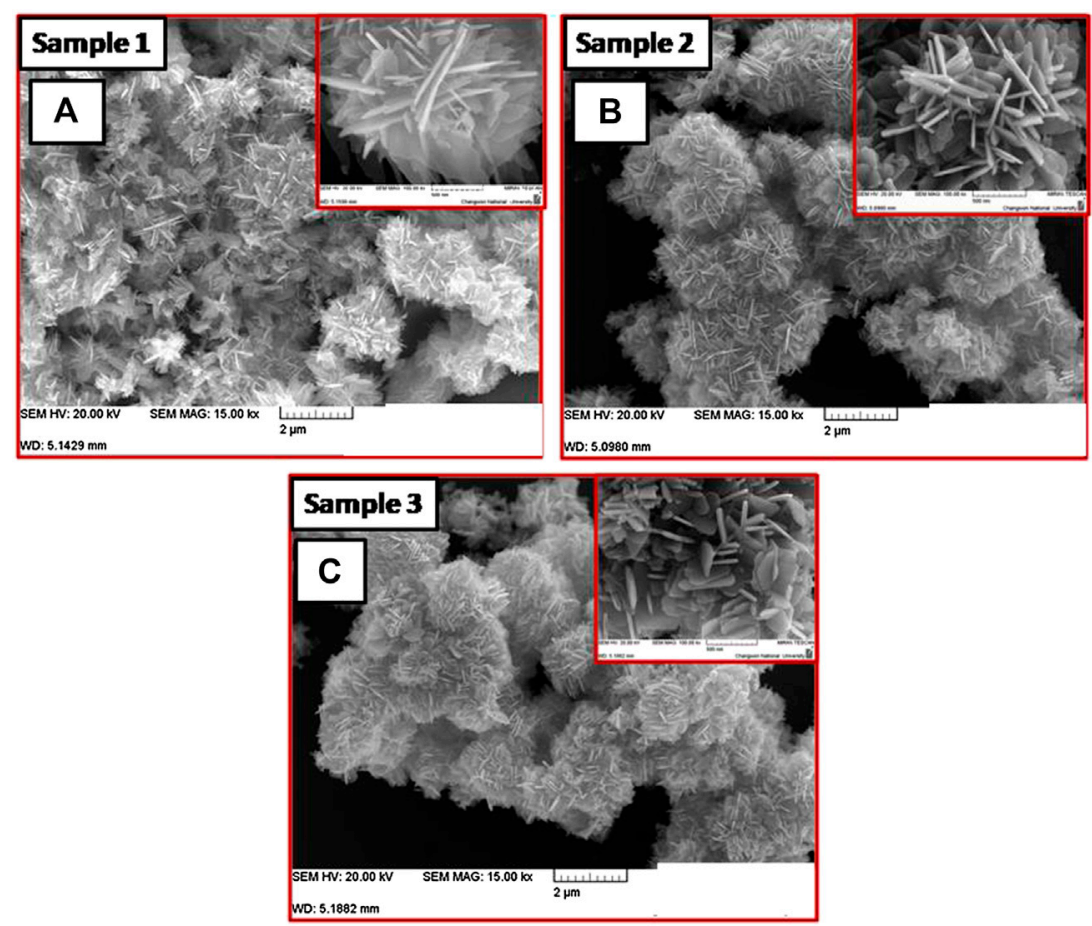

FIGURE 2 | FESEM images of ZnO nanosheets for (A) sample 1 (1:2.5) (B) sample 2 (1:2.75), and (C) sample 3 (1:5).

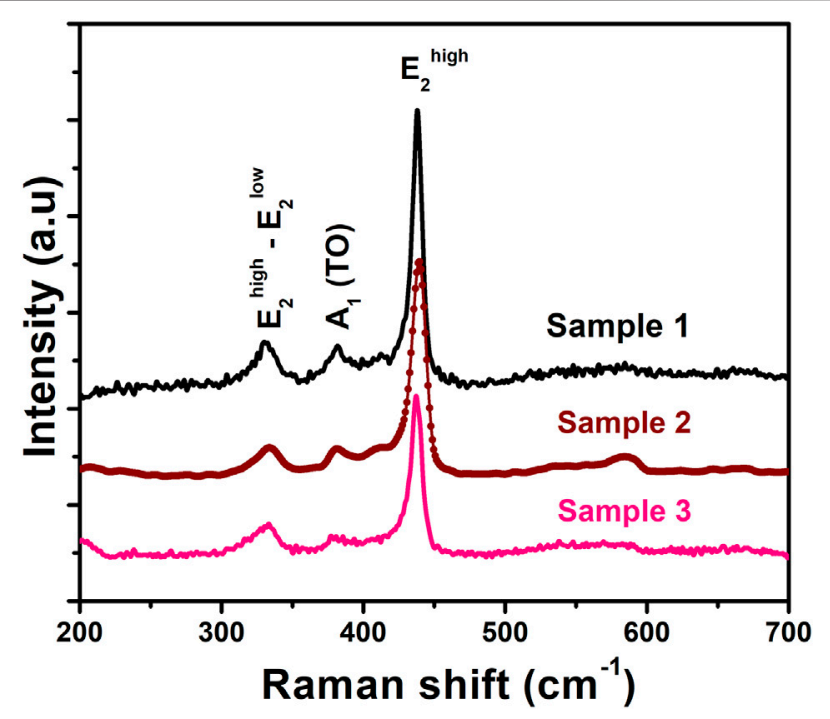

FIGURE 3 | Raman spectra of ZnO nanosheets for sample 1, sample 2, and sample 3.

a surface area of $145^{\circ} \mathrm{m}^{2} / \mathrm{g}$ for sample 2, and a surface area of $94^{\circ} \mathrm{m}^{2} / \mathrm{g}$ for sample 3 , respectively. These surface areas are in good agreement with the fact that the smaller the size, the higher the surface area. Therefore, thinner nanosheets (sample 1) showed a higher surface area.
Photocatalytic properties of the $\mathrm{ZnO}$ nanosheets with different thicknesses were examined by decomposition of MR. For the photocatalytic degradation process, a characteristic absorption of $\mathrm{MR}$ at $\sim 428 \mathrm{~nm}$ was chosen. Figures $4 \mathrm{~A}$ shows the timedependent absorption spectra of MR aqueous solutions during the UV light irradiation with $\mathrm{ZnO}$ nanosheets (sample 1). As a control, the absorbtion peak was monitored with two different conditions: 1) with a photocatalyst in the dark and 2) without photocatalysts under UV light irradiation. No change in absorbtion peak of MR under these conditions was found, indicating no loss of MR without an irradiated photocatalyst. Further, the photocatalytic performance of $\sim 50 \%$ is obtained for $\mathrm{ZnO}$ nanosheets (sample 1) in MR solution within $20 \mathrm{~min}$ of photoirradiation; however, MR was almost completely removed after 240 min illumination of UV light.

The relative concentration $\left(\mathrm{C} / \mathrm{C}_{0}\right)$ of $\mathrm{MR}$ with time for various nanosheets with different thicknesses is shown in Figures 4B, where $\mathrm{C}$ is the concentration of $\mathrm{MR}$ at the irradiation time $(\mathrm{t})$ and $\mathrm{C}_{0}$ is the concentration of the dye before irradiation. Figures $4 \mathrm{~B}$ reveals that for all the $\mathrm{ZnO}$ nanosheets used in the MR solution, the MR concentration is found to decrease with irradiation time, symbolizing that all the nanosheets are efficient UV-light photocatalysts. The catalytic activity of these nanosheets have a sequence of sample $1>$ sample $2>$ sample 3 for $240 \mathrm{~min}$ of irradiation, concluding that the thinner the nanosheets, the higher the photocatalytic activity.

The kinetic behaviors of these photocatalysts were further studied as shown in Figures 5A. There is a clear linear relationship between $\ln \left(\mathrm{C}_{0} / \mathrm{C}\right)$ and the irradiation time. The 

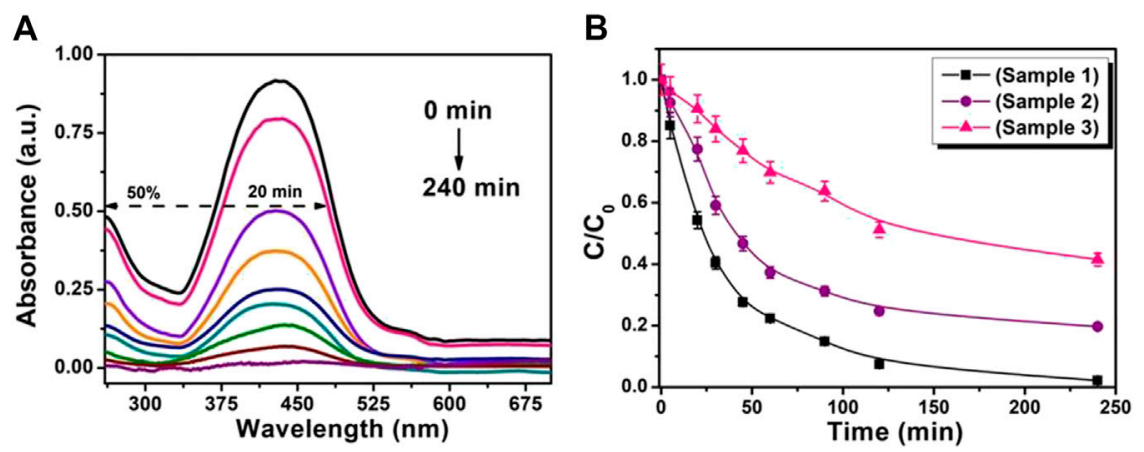

FIGURE 4 | (A) UV-visible absorbance spectra of photodegradation of MR in the presence of ZnO nanosheets (sample 1). (B) Temporal evolution of MR absorption spectra with various $\mathrm{ZnO}$ nanosheets photocatalysts.
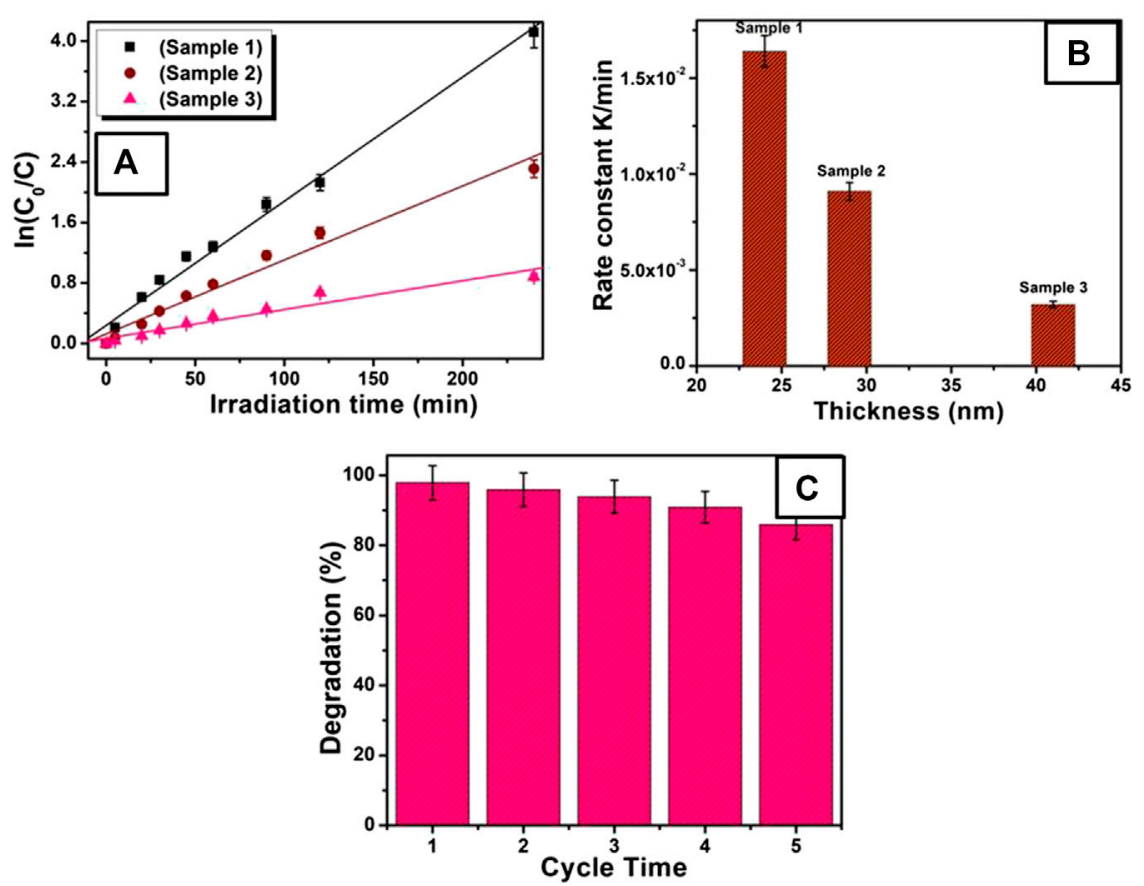

FIGURE 5 | (A) Kinetic relationship of In $\left(\mathrm{C}_{0} / \mathrm{C}\right)$ vs. irradiation time, for various ZnO nanosheet photocatalysts. (B) Plot of rate constant vs thickness of nanosheets. (C) The stability of ZnO nanosheets (sample 1) for photodegradation of MR.

photocatalytic process can be regarded as a pseudo-first-order reaction with the rate equation $\ln \left(\mathrm{C}_{0} / \mathrm{C}\right)=\mathrm{Kt}$, where, $\mathrm{t}$ is reaction time, $\mathrm{K}$ is the apparent reaction rate constant, and $\mathrm{C}_{0}$ and $\mathrm{C}$ are the concentration of MR at 0 and t time, respectively. Figures 5B gives the relation between reaction rate $\mathrm{k}$ and nanosheets with different thickness. The apparent reaction rate constant $\mathrm{K}$ for the degradation of MR was calculated to be $1.60 \times 10^{-2}{ }^{\circ} \mathrm{min}^{-1}, 9.10 \times$ $10^{-3 \circ} \mathrm{min}^{-1}$, and $3.18 \times 10^{-3 \circ} \mathrm{min}^{-1}$ for $\mathrm{ZnO}$ nanosheets with thicknesses of $\sim 24 \mathrm{~nm}$ (sample 1), $\sim 29 \mathrm{~nm}$ (sample 2), and $\sim 50 \mathrm{~nm}$ (sample 3), respectively. As can be seen from inset of Figures $\mathbf{5 B}$, the reaction rate constant is higher for thinner nanosheets (sample 1) than for the thicker one (sample 3), signifying higher photocatalytic activity of thinner $\mathrm{ZnO}$ nanosheets.
Additionally, comparing the photocatalytic activity of other previously reported nanostructures with the thinner $\mathrm{ZnO}$ nanosheets (sample 1) obtained in the present study, it is found that $\mathrm{ZnO}$ nanosheets showed better photocatalytic behavior. Comparelli et al. (2004) showed the degradation to be $50 \%$ of $\mathrm{MR}$ with nanosized $\mathrm{ZnO}$, and $90 \%$ of $\mathrm{MR}$ with nanosized $\mathrm{TiO}_{2}$ for 140 min under UV irradiation. Kanjwal et al. (2010) showed that the hierarchical nanostructure of $\mathrm{ZnO}-\mathrm{TiO}_{2}$ can remove almost all the MR dye within $90 \mathrm{~min}$ of irradiation time; moreover, pure $\mathrm{ZnO}$ nanoflowers removed less than $30 \%$ of MR dye, even after $180 \mathrm{~min}$. However, for pristine $\mathrm{TiO}_{2}$ nanofibers, up to $50 \%$ of the dye was removed after $180 \mathrm{~min}$. In the present work, more than $50 \%$ of MR was degraded by $\mathrm{ZnO}$ nanosheets (sample 1) within $20 \mathrm{~min}$ and 
almost completely degraded for 240 min of UV light irradiation. Therefore, thin $\mathrm{ZnO}$ nanosheets obtained in the present work are far better photocatalysts than others, taking care that the experimental conditions in the above mentioned previous reports might be different.

The main criterion for the development of photocatalysts for organic dye degradation is its stability. In order to estimate the photocatalytic stability of the $\mathrm{ZnO}$ nanosheets, a time track for photocatalytic degradation of $\mathrm{MR}$ using thin $\mathrm{ZnO}$ nanosheets (sample 1) was recorded as shown in Figures 5C. For repeated runs, slight change in the degradation of MR was found for the photocatalytic reaction at $60 \mathrm{~min}$, which shows that thinner $\mathrm{ZnO}$ nanosheets are stable. So, it can be used as a potential candidate for practical photocatalysis applications.

Several factors such as carrier recombination, size of the particles, surface area, surface acidity, and presence of higher number of hydroxyl groups are responsible for the photocatalytic activity of a catalytic material. In this work, thinner $\mathrm{ZnO}$ nanosheets (sample 1) show a higher percentage of degradation as compared to the thicker nanosheets as well as previously reported work. The enhancement of photocatalytic activity can be attributed to the relative increase of the active morphological surface due to the increased surface to volume ratio and low recombination rate of electron hole pairs, generated by optical exposure, owing to largely available surface states.

Photocatalytic degradation process is due to the action of hydroxyl radicals formed during the reaction (Zhang et al., 2009b). The mechanism is as follows: On illumination of $\mathrm{ZnO}$ nanosheets with light, electrons get excited from the valence band to the conduction band of $\mathrm{ZnO}$, leaving a hole in the valence band. The hydroxyl groups present on the surface of the $\mathrm{ZnO}$ nanosheets react with the photogenerated hole to produce hydroxyl radicals. Also, dissolved oxygen interacts with photogenerated electrons to form peroxide $\left(\mathrm{O}_{2}{ }^{-}\right)$. This peroxide takes one proton to form a superoxide $\left(\mathrm{HO}_{2}^{-}\right)$and then hydrogen peroxide $\left(\mathrm{H}_{2} \mathrm{O}_{2}\right)$.

$$
\begin{aligned}
& \mathrm{ZnO}+h v \rightarrow \mathrm{ZnO}+e^{-}+h^{+} \\
& \mathrm{OH}^{-}+h^{+} \rightarrow \mathrm{OH}^{-} \\
& \mathrm{O}_{2}+e^{-} \rightarrow \mathrm{O}_{2}^{-} \text {...... } \\
& \mathrm{O}_{2}^{-}+\mathrm{H}^{+} \rightarrow \mathrm{HO}_{2} \\
& 2 \mathrm{HO}_{2} \rightarrow \mathrm{H}_{2} \mathrm{O}_{2}+\mathrm{O}_{2} \ldots \ldots \ldots \text {.... (5) } \\
& \mathrm{H}_{2} \mathrm{O}_{2}+e^{-} \rightarrow \mathrm{OH}^{-}+\mathrm{OH}^{-}
\end{aligned}
$$

A hydroxyl radical was also produced by the attack of a photogenerated electron to the hydrogen peroxide. These

\section{REFERENCES}

Ahmed, F., Kumar, S., Arshi, N., Anwar, M. S., Koo, B. H., and Lee, C. G. (2011). Rapid and cost effective synthesis of zno nanorods using microwave irradiation technique. Funct. Mater. Lett. 04, 1-5. doi:10.1142/s1793604711001531

Baruah, S., and Dutta, J. (2009). Hydrothermal growth of $\mathrm{ZnO}$ nanostructures. Sci. Technol. Adv. Mater. 10, 013001. doi:10.1088/1468-6996/10/1/013001

Baruah, S., Rafique, R. F., and Dutta, J. (2008). Visible light photocatalysis by tailoring crystal defects in zinc oxide nanostructures. Nano 3, 8.

Becker, J., Raghupathi, K. R., St. Pierre, J., Zhao, D., and Koodali, R. T. (2011). Tuning of the crystallite and particle sizes of $\mathrm{ZnO}$ nanocrystalline materials in reactive radicals and intermediate species react with dye and degrade them into non-toxic organic compounds.

\section{CONCLUSION}

Highly-crystalline $\mathrm{ZnO}$ nanosheets with different thicknesses have been prepared by a simple microwave-hydrothermal assisted solution method. XRD, HRTEM, SAED, and Raman analyses explained that $\mathrm{ZnO}$ nanosheets are of hexagonal phase structure. FESEM images showed that the thickness of $\mathrm{ZnO}$ nanosheets could be efficiently controlled by changing the molar ratio. Increasing the molar ratio increases the thickness of the nanosheets and decreases the lateral dimension. Raman measurements confirmed the characteristic mode $\mathrm{E}_{2}{ }^{\text {high }}$ of $\mathrm{ZnO}$ nanosheets. Photodegradation results show that the thinner $\mathrm{ZnO}$ nanosheet (sample 1) is capable of degrading $~ 50 \%$ of MR within $20 \mathrm{~min}$ and degrades $\mathrm{MR}$ almost completely on increasing irradiation time to $240 \mathrm{~min}$. This improvement in photocatalytic activity might be due to the easy separation of photogenerated charge carriers in the thinner nanosheets which resulted in the enhanced oxygen chemisorptions. Considering this outstanding photocatalytic performance, and simple preparation method, the prepared $\mathrm{ZnO}$ nanosheets are believed to have potential applications in photocatalysis and environmental remediation.

\section{DATA AVAILABILITY STATEMENT}

The raw data supporting the conclusions of this article will be made available by the authors, without undue reservation.

\section{AUTHOR CONTRIBUTIONS}

AA designed the experiment to execute the concept. AA performed the analyses, and wrote the manuscript.

\section{ACKNOWLEDGMENTS}

The author would like to thank the Deanship of Scientific Research at King Faisal University for supporting this research through NASHER track (grant \# 186106).

solvothermal synthesis and their photocatalytic activity for dye degradation. J. Phys. Chem. C 115, 13844. doi:10.1021/jp2038653

Bohle, D. S., and Spina, C. J. (2009). Cationic and anionic surface binding sites on nanocrystalline zinc oxide: surface influence on photoluminescence and photocatalysis. J. Am. Chem. Soc. 131, 4397. doi:10.1021/ja808663b

Carraway, E. R., Hoffman, A. J., and Hoffmann, M. R. (1994). Photocatalytic oxidation of organic acids on quantum-sized semiconductor colloids, Environ. Sci. Technol. 28, 786. doi:10.1021/es00054a007

Chatterjee, D., and Dasgupta, S. (2005). Visible light induced photocatalytic degradation of organic pollutants, J. Photochem. Photobiol. C Photochem. Rev. 6, 186. doi:10.1016/j.jphotochemrev.2005.09.001 
Comparelli, R., Cozzoli, P. D., Curri, M. L., Agostiano, A., Mascolo, G., and Lovecchio, G. (2004). Photocatalytic degradation of methyl-red by immobilised nanoparticles of $\mathrm{TiO} 2$ and $\mathrm{ZnO}$. Water Sci. Technol. 49, 183. doi:10.2166/wst. 2004.0257

Comparelli, R., Fanizza, E., Curri, M. L., Cozzi, P. D., Mascolo, G., and Agostiano, A. (2005). Photocatalytic degradation of azo dyes by organic-capped anatase TiO2 nanocrystals immobilized onto substrates. Appl. Catal., B 1, 60.

Cusco, R., Alarcon-Llado, E., Ibanez, J., Artus, L., Jimenez, J., Wang, B. G., et al. (2007). Temperature dependence of Raman scattering in ZnO. Phys. Rev. B 75, 165202. doi:10.1103/physrevb.75.165202

Dong, J.-Y., Lin, C.-H., Hsu, Y.-J., Lu, S.-Y., and Wong, D. S.-H. (2012). Singlecrystalline mesoporous $\mathrm{ZnO}$ nanosheets prepared with a green antisolvent method exhibiting excellent photocatalytic efficiencies. Crystengcomm 14, 4732-4737. doi:10.1039/c2ce06739k

Hosono, E., Fujihara, S., Honma, I., and Zhou, H. (2005). The fabrication of an upright-standing zinc oxide nanosheet for use in dye-sensitized solar cells. $A d v$. Mater. 17, 2091-2094. doi:10.1002/adma.200500275

Hu, J., Zhu, K., Chen, L., Yang, H., Li, Z., Suchopar, A., et al. (2008). Preparation and surface activity of single-crystalline $\mathrm{NiO}(111)$ nanosheets with hexagonal holes: a semiconductor nanospanner. Adv. Mater. 20, 267-271. doi:10.1002/ adma.200701389

Huang, M. H., Mao, S., Feick, H., Yan, H. Q., Wu, Y. Y., Kind, H., et al. (2001). Room-temperature ultraviolet nanowire nanolasers. Science 292, 1897-1899. doi:10.1126/science.1060367

Jang, E. S., Won, J.-H., Hwang, S.-J., and Choy, J.-H. (2006). Fine tuning of the face orientation of $\mathrm{ZnO}$ crystals to optimize their photocatalytic activity. Adv. Mater. 18, 3309. doi:10.1002/adma.200601455

Jing, Z. H., and Zhan, J. H. (2008). Fabrication and gas-sensing properties of porous $\mathrm{ZnO}$ nanoplates. Adv. Mater. 20, 4547. doi:10.1002/adma.200800243

Kanjwal, M. A., Barakat, N. A. M., Sheikh, F. A., Park, S. J., and Kim, H. Y. (2010). Photocatalytic activity of $\mathrm{ZnO}-\mathrm{TiO} 2$ hierarchical nanostructure prepared by combined electrospinning and hydrothermal techniques. Macromol. Res. 18, 233. doi:10.1007/s13233-010-0303-9

Kong, X. Y., and Wang, Z. L. (2004). Polar-surface dominated $\mathrm{ZnO}$ nanobelts and the electrostatic energy induced nanohelixes, nanosprings, and nanospirals. Appl. Phys. Lett. 84, 975. doi:10.1063/1.1646453

Kumar, S. G., and Rao, K. S. R. K. (2015). Zinc oxide based photocatalysis: tailoring surface-bulk structure and related interfacial charge carrier dynamics for better environmental applications. RSC Adv. 5, 3306. doi:10.1039/c4ra13299h

Li, G.-R., Lu, X.-H., Zhao, W.-X., Su, C.-Y., and Tong, Y.-X. (2008). Controllable electrochemical synthesis of $\mathrm{Ce} 4+$-doped $\mathrm{ZnO}$ nanostructures from nanotubes to nanorods and nanocages. Cryst. Growth Des. 8, 1276. doi:10.1021/cg7009995

Linsebigler, A., Lu, G., and Yates, J. T. (1995). Photocatalysis on TiO2 surfaces: principles, mechanisms, and selected results. Chem. Rev. 95, 735-758. doi:10. $1021 / \mathrm{cr} 00035 \mathrm{a} 013$

Liu, J., Guo, Z., Meng, F., Luo, T., Li, M., and Liu, J. (2009). Novel porous single-crystalline $\mathrm{ZnO}$ nanosheets fabricated by annealing $\mathrm{ZnS}(\mathrm{en}) 0.5$ (en = ethylenediamine) precursor. Application in a gas sensor for indoor air contaminant detection, Nanotechnology 20, 125501. doi:10.1088/0957-4484/20/12/125501

Marković, S., Simatović, I. S., Ahmetović, S., Veselinović, L., Stojadinović, S., Rac, V., et al. (2019) Surfactant-assisted microwave processing of $\mathrm{ZnO}$ particles: a simple way for designing the surface-to-bulk defect ratio and improving photo(electro)catalytic properties. RSC Adv. 9, 17165

Nagy, G. D., and Casey, E. J. (1971). Wiley, 29-36.

Pan, Z. W., Dai, Z. R., and Wang, Z. L. (2001). Nanobelts of semiconducting oxides. Science 291, 1947. doi:10.1126/science. 1058120
Poulios, I., Makri, D., and Prohaska, X. (1999) Photocatalytic treatment of olive milling waste water: oxidation of protocatechuic acid. Global Nest: Int. J. 1, 55.

Qiu, M., Ye, Z., Lu, J., He, H., Huang, J., Zhu, L., et al. (2009). Growth and properties of $\mathrm{ZnO}$ nanorod and nanonails by thermal evaporation. Appl. Surf. Sci. 255, 3972. doi:10.1016/j.apsusc.2008.10.093

Qiu, Y. C., Chen, W., and Yang, S. H. (2010). Facile hydrothermal preparation of hierarchically assembled, porous single-crystalline $\mathrm{ZnO}$ nanoplates and their application in dye-sensitized solar cells. J. Mater. Chem. 20, 1001. doi:10.1039/ b917305f

Thompson, T. L., and Yates, J. T. (2006). Surface science studies of the photoactivation of $\mathrm{TiO} 2 \mathrm{New}$ photochemical processes. Chem. Rev. 106, 4428. doi:10.1021/cr050172k

Tien, L. C., Norton, D. P., Pearton, S. J., Wang, H.-T., and Ren, F. (2007). Nucleation control for $\mathrm{ZnO}$ nanorods grown by catalyst-driven molecular beam epitaxy. Appl. Surf. Sci. 253, 4620. doi:10.1016/j. apsusc.2006.10.012

Wang, J., Liu, P., Fu, X., Li, Z., Han, W., and Wang, X. (2009). Relationship between oxygen defects and the photocatalytic property of $\mathrm{ZnO}$ nanocrystals in nafion membranes. Langmuir 25, 1218. doi:10.1021/la803370z

Wang, Y. W., Zhang, L. Z., Deng, K. J., Chen, X. Y., and Zou, Z. G. (2007). Low temperature synthesis and photocatalytic activity of rutile TiO2Nanorod superstructures. J. Phys. Chem. C 111, 2709. doi:10.1021/jp066519k

$\mathrm{Wu}$, J.-J., and Tseng, C.-H. (2006). Photocatalytic properties of nc-Au/ZnO nanorod composites. Appl. Catal. B Environ. 66, 51. doi:10.1016/j.apcatb. 2006.02.013

Wu, J.-J., Liu, S.-C., Wu, C.-T., Hen, C. K. H., and Chen, L.-C. (2002). Heterostructures of $\mathrm{ZnO}-\mathrm{Zn}$ coaxial nanocables and $\mathrm{ZnO}$ nanotubes. Appl. Phys. Lett. 81, 1312. doi:10.1063/1.1499512

Zeng, Y.-J., Ye, Z.-Z., Xu, W.-Z., Zhu, L.-P., and Zhao, B.-H. (2005). Well-aligned $\mathrm{ZnO}$ nanowires grown on $\mathrm{Si}$ substrate via metal-organic chemical vapor deposition. Appl. Surf. Sci. 250, 280. doi:10.1016/j.apsusc.2005.03.140

Zhang, J., Wang, S., Xu, M., Wang, Y., Zhu, B., Zhang, S., et al. (2009a). Hierarchically porous $\mathrm{ZnO}$ architectures for gas sensor application. Cryst. Growth Des. 9, 3532. doi:10.1021/cg900269a

Zhang, L.-S., Wong, K.-H., Zhang, D.-Q., Hu, C., Yu, J. C., Chan, C.-Y., et al. (2009b). Zn:In(OH)ySzSolid solution nanoplates: synthesis, characterization, and photocatalytic mechanism. Environ. Sci. Technol. 43, 7883. doi:10.1021/ es902013d

Zhang, Y., Jia, H. B., Wang, R. M., Chen, C. P., Luo, X. H., Yu, D. P., et al. (2003). Low-temperature growth and Raman scattering study of vertically aligned ZnO nanowires on Si substrate. Appl. Phys. Lett. 83, 4631. doi:10.1063/1. 1630849

Zhou, X. F., Hu, Z. L., Fan, Y. Q., Chen, S., Ding, W. P., and Xu, N. P. (2008). Hollow microsphere assembly of $\mathrm{ZnO}$ nanosheets. J. Phys. Chem. C 112, 11722. doi:10.1016/j.matchemphys.2008.06.025

Conflict of Interest: The authors declare that the research was conducted in the absence of any commercial or financial relationships that could be construed as a potential conflict of interest.

Copyright (c) 2020 Aljaafari. This is an open-access article distributed under the terms of the Creative Commons Attribution License (CC BY). The use, distribution or reproduction in other forums is permitted, provided the original author(s) and the copyright owner(s) are credited and that the original publication in this journal is cited, in accordance with accepted academic practice. No use, distribution or reproduction is permitted which does not comply with these terms. 